\title{
Los derechos homínidos. Una defensa ecuménica
}

\author{
Simian Rights. An Ecumenical Defence
}

PAULA CASAL*

\begin{abstract}
Resumen: Hay quien rechaza los derechos homínidos afirmando que son fruto de una confusión conceptual. Sin embargo, aunque hay muchas disputas filosóficas acerca de si existen derechos naturales o derechos a recibir ayuda, sobre la plausibilidad de las teorías del status y la elección, o sobre la concepción de los derechos como triunfos o constricciones, la opinión mayoritaria en todos esos debates es perfectamente compatible con el concepto de derechos simios. De hecho, los derechos de los gorilas, orangutanes, chimpancés, bonobos y humanos pueden defenderse desde cualquier posición en esos debates e incluso desde cualquier combinación de posiciones en esos debates.

Palabras clave: Derechos animales, derechos humanos, derechos positivos, teoría del status y teoría electiva de los derechos.
\end{abstract}

\begin{abstract}
Some reject hominid rights arguing they are the product of conceptual confusion. However, although there are many philosophical disputes regarding, for example, the existence of natural rights, of rights to be aided, as well as regarding the plausibility of the status or the choice theory of rights or the conception of rights as trumps or side-constraints, the majority opinion in all these debates is perfectly compatible with the concept of simian rights. In fact, gorilla, orang-utan, chimpanzee, bonobo and human rights can be defended from any position in those debates and even any combination of positions in those debates.
\end{abstract}

Keywords: Animal rights, human rights, positive rights, status and choice theories of rights.

\section{Introducción: cinco debates}

Aunque la idea de los derechos humanos no es reciente -los del hombre se declararon públicamente en 1789 y Marie Gouze declaró los de la mujer en 1791- tras los horrores de la II Guerra Mundial se generó un amplio consenso sobre los derechos humanos. Normalmente, se consideran una forma de protección moral y legal de carácter universal, e inalienable, y que son derechos naturales, porque existían antes de ser reconocidos y declarados en algún acto social como la Declaración Universal en la Asamblea General de las Naciones

Recibido: 16/01/2015. Aceptado: 26/03/2015.

* Professor of Moral and Political Philosophy, ICREA y Universidad Pompeu Fabra. paula.casal@upf.edu. Publicaciones recientes (2016): Un reparto más justo del planeta (Trotta, Madrid, 2016) con Thomas Pogge y Hillel Steiner, "Mill, Rawls and Cohen on Incentives and Occupational Freedom" Utilitas 29.4 (2016): 375-97. Se agradece la financiación del Proyecto MINECO Retos DER2016-80471-C-2-R. 
Unidas de 1948. Las justificaciones de los derechos humanos en general apelan a veces a expresiones retóricas, vagas y no verificables como «la dignidad intrínseca del ser humano», que nadie sabe bien qué significa (Beitz, 2013), aun si comprendemos que se apele a estos valores como reacción a los abusos nazis. En cambio, la defensa de cada derecho suele apelar a intereses más fácilmente identificables que cada derecho vendría a proteger. Ni los filósofos, ni los políticos, ni el público en general está igualmente familiarizado con el concepto de derecho homínido o simio, que es el que corresponde no sólo a los humanos, sino también a sus hermanos evolutivos los bonobos, chimpancés, gorilas y orangutanes, que forman el grupo de los grandes simios antropoides ${ }^{1}$. A consecuencia de ello, la existencia de los derechos homínidos se niega con mayor frecuencia que la existencia de los derechos humanos (que también algunos niegan).

$\mathrm{Al}$ igual que ocurre con quienes rechazan los derechos humanos, quienes rechazan los derechos homínidos no suelen argumentar que no hay nada malo en matar, encarcelar o maltratar a los sujetos de estos derechos. Su discurso es casi siempre que quienes defienden estos derechos lo hacen en base a teorías erróneas, sectarias o minoritarias o que son víctimas de algún tipo de confusión conceptual. Esta estrategia es más efectiva que insistir en que estos seres no importan y da la impresión de que el detractor es intelectualmente superior al compasivo, bien intencionado, pero profundamente confundido defensor de los derechos homínidos o humanos. Como esta estrategia no revela interés propio o falta de sensibilidad moral viene bien a los que se han enriquecido en instituciones que explotan a los homínidos, a los que consideran su ideología religiosa amenazada por el concepto de derecho homínido y a los que simplemente desean aparentar superioridad intelectual, pese a carecer de una formación filosófica superior a la de defensores de los derechos homínidos como Gary Francione, Robert Goodin, Lori Gruen, Dale Jamieson, Colin McGinn, Ingmar Persson, Carol Pateman, James Rachels, Tom Regan, Peter Singer o Steve Wise ${ }^{2}$. Esto no significa que no haya buenas personas que simplemente no creen, con toda sinceridad, en la existencia de los derechos homínidos, o tampoco de los derechos humanos. No sólo las hay, sino que no es demasiado sorprendente que las haya, teniendo en cuenta el desacuerdo -y no sólo la confusión- que hay en torno a los derechos. La idea de que defender los derechos simios supone asumir posiciones excéntricas o claramente minoritarias en alguno de estos debates no parece en principio improbable. Sin embargo, como explicaré en este artículo, aunque existen profundos desacuerdos en torno a la naturaleza de los derechos, su función y su fundamentación, los derechos homínidos pueden defenderse -de forma distinta, claro-

1 Antes del la llegada de la ciencia genómica, se clasificaban las especies por sus apariencias, y la super-familia hominoide se dividía en tres familias: los hilobátidos o pequeños simios, los póngidos o grandes simios y los homínidos o humanos con sus antepasados bípedos. Hoy en día, mientras que los humanos y sus antepasados bípedos se llaman homíninos, los homínidos son todos los grandes simios, humanos incluidos. Se dividen en la subfamilia Ponginae, donde están solo los orangutanes y la Homininae donde están los demás. Además, algunos también incluyen en el género Homo a los humanos, los bonobos y los chimpancés (Véase Berger 2001).

2 Francione, Jamieson, McGinn, Persson, Rachels y Reagan contribuyeron a The Great Ape Project (Cavalieri y Singer 1993), Goodin y Pateman han defendido los derechos territoriales de los simios (Goodin y Pateman 1997); la destacada catedrática de filosofía Lori Gruen ha dedicado buena parte de su vida a defenderlos y Steve Wise (2000) ha enseñado derechos simios en Harvard. Todos son autores de primera línea, que han hablado de los derechos en las mejores universidades y cuentan con una amplia producción filosófica, publicada en editoriales y revistas de prestigio. 
desde cada una de las posturas enfrentadas en estos debates. Y si podemos defender los derechos simios desde cualquiera de las teorías enfrentadas, también podremos, a fortiori, defender los derechos humanos desde cualquiera de ellas.

En el campo de la ética y la filosofía política contemporánea existen al menos cinco debates fundamentales relativos a los derechos y espero que explicarlos brevemente sea útil al lector. El primer debate se adscribe a veces al campo de la meta-ética y concierne al origen de los derechos. Para algunos hay derechos naturales, independientes de que la gente haga algo, como firmar un acuerdo (Hart, 1955). Para otros, todos los derechos son artefactos culturales que se derivan de algo que hacen las personas, de alguna tradición o costumbre, o de algún acuerdo o contrato social. Esta disputa se asocia a veces con la meta-ética, entre otras razones, porque con frecuencia está relacionada con la cuestión de si hay una serie de cosas que ningún gobierno debería poder hacernos, independientemente del contexto cultural en que uno esté y de los distintos contratos sociales vigentes en cada caso.

Los tres debates siguientes son debates de ética normativa. En primer lugar, los filósofos, debaten la base de los derechos, que para unos está en el estatus moral o las características de los sujetos de los derechos y para otros en el papel que los derechos juegan en la prevención del mal. Un segundo debate, tan íntimamente vinculado al anterior que casi se confunde con él, es el de si la función (o la justificación) de los derechos es la protección de intereses fundamentales o algo derivado de que algunos individuos sean criaturas racionales con la capacidad de elegir y decidir sobre sus cuerpos y sus vidas. Por último, no hay acuerdo sobre si debemos considerar la protección de los derechos como una meta o como una constricción (side-constraint). La quinta y última cuestión es la de si sólo hay derechos negativos o derechos a que no interfieran deliberadamente con nuestros planes o si también hay derechos positivos, por ejemplo, a la educación o la asistencia médica. Este debate corresponde todavía al campo normativo, aunque la discusión sobre qué derechos concretos son los que tienen los simios o algún otro grupo podría considerarse ya una cuestión de ética aplicada.

Seguiré este orden. Tras ofrecer algunas razones para reconocer a los simios al menos tres derechos básicos (sección II), expondré el debate entre los derechos naturales y artificiales (sección III), el debate sobre si los derechos se explican por el estatus moral de sus poseedores o por la función que desempeñan (sección IV), el debate sobre si los derechos protegen intereses importantes o son algo propio de los individuos que pueden elegir, les beneficie o no (sección V), el debate sobre si los derechos son metas o constricciones (VI) y el debate sobre la existencia de derechos positivos (VII). La idea general es mostrar que es posible defender los derechos simios desde cada una de las posiciones enfrentadas en estos debates, pero que es más fácil defenderlos desde las posiciones mayoritarias en cada debate. Por tanto, para defender los derechos homínidos, no sólo no es necesario, sino que ni siquiera es conveniente, defender posturas extrañas o minoritarias en cuanto a los derechos en general.

Una última cuestión que conviene aclarar es que defender los derechos homínidos tampoco supone negar los derechos de otros animales. En primer lugar, hay otras especies capaces de reconocerse en un espejo, con capacidades cognitivas y emotivas semejantes a las de los grandes simios (como los delfines, las orcas y los elefantes) a los que serían aplicables argumentos parecidos. Y hay argumentos relativos al dolor que son aplicables a 
todos los animales. No obstante, no es buena idea intentar hacerlo todo en un solo artículo y por tanto aquí me restringiré al objetivo, probablemente exportable a otros casos, de mostrar que defender los derechos simios no requiere adoptar posturas filosóficas excéntricas.

\section{Tres derechos}

\section{II.1. La muerte}

Morir es malo, en primer lugar, porque nos priva de todas las experiencias que podríamos tener de seguir vivos (Nagel, 1979, 1ff). Si un mosquito pierde la vida, pierde sólo unos días (o, en algunas especies, semanas) de andar revoloteando por ahí, sin rumbo, ni compañía. Los homínidos, en cambio, tenemos mucho que perder al perder la vida: somos longevos y tenemos vidas complejas e interesantes, fuertes lazos familiares y sociales, amistades, inventos, viajes, actividades lúdicas y creativas que enriquecen nuestras vidas. Por ello tenemos también un interés muy importante en conservarla. Esta es la primera consideración relevante y quizá la menos discutible.

La segunda consideración es que mientras que nadie llorará al mosquito, ni notará su ausencia, los homínidos tenemos lazos sociales y familiares tan intensos que nuestra muerte puede ser incluso peor para nuestras familias y amigos que para nosotros mismos. Podemos llegar a enloquecer o morir de pena por la muerte de un ser querido. Esta es la segunda consideración relevante.

La tercera y última consideración es más compleja. Si el mosquito sigue vivo, no lo apreciará igualmente porque no sabrá que sigue vivo. Ni siquiera sabe que es un mosquito. $\mathrm{O}$ tomemos el caso de un ser longevo como algunos de los peces de estanque capaces de vivir varias décadas. Si el mismo pez no sabe que es el mismo pez que estaba el verano pasado en ese estanque, no está claro que (moralmente) sea mejor que se trate del mismo pez (un pez que dura cuarenta años) o que haya dos peces que duren veinte cada uno. Esto apunta a un tercer factor. La muerte no sólo es mala según lo que perdamos al perder la vida, y lo que pierdan aquellos que nos aprecian, sino que también depende de nuestra contigüidad psicológica y nuestra conexión con el futuro (McMahan, 2002), es decir, del sentido que tenemos los homínidos de nosotros mismos como seres pensantes que existen en el tiempo, y de nuestra capacidad de pensar aquello que aun no ha ocurrido (Cavalieri y Singer 1993, 28-80, Osvath y Martin-Ordas 2015; Osvath y Osvath 2008; Marshall et al. 1994). Si sólo tuviésemos en cuenta los dos primeros factores no sería fácil explicar por qué consideramos más trágica la muerte de un niño que la de un embrión, si no hay una familia que sufra más lo uno que lo otro ${ }^{3}$. Un embrión tiene más que perder que un bebé y un bebé tiene más que perder que un niño, porque le quedan todavía más años por delante. El niño, sin embargo, ya

3 De hecho, algunos autores (Lara y Campos 2015, 61) rechazan la idea de que lo malo de la muerte dependa en parte de las posibles experiencias que uno se pierda al perder la vida, argumentando que entonces matar a cualquiera que tenga algo que perder sería también malo en algún grado y que esto no es plausible. Creo que no solo es plausible, sino que es de esperar que haya más de una razón válida para no matar y que algunas razones válidas para no matar a los homínidos sean razones para no matar a un grupo mucho más amplio de individuos, mientras que otras razones, como la razón que Lara y Campos aceptan (2015, 69), solo es aplicable a los animales auto-conscientes, es decir, los homínidos, los elefantes, algunos cetáceos y la urraca europea. 
tiene contigüidad psicológica y ya quiere ser médico o piloto. Ya tiene planes y esperanzas y se prepara para el mañana. Una muerte prematura cortaría súbitamente ese vínculo que conecta al niño con su futuro y que a cierta edad empieza a ser tan intenso que nos lleva a sacrificarnos por ese futuro y a vivir ya mentalmente en él. Llega un punto en que casi todo lo que hacemos lo hacemos pensando en el futuro y si ese futuro no llega nuestros esfuerzos habrán sido en vano. Nuestra relación con nuestro futuro es tan íntima, intensa y omnipresente que cercenar esa unión es como cortar una parte de nosotros mismos. Otros animales, en cambio, no tienen futuro en el sentido de que no pueden pensarlo ni actuar con el futuro en mente. Cuando su futuro llega, aunque sigan habitando el mismo cuerpo, ya son criaturas mentalmente disociadas de la criatura que fueron anteriormente. La intensa conexión del homínido con su futuro da sentido a su vida y hace su muerte más trágica y por ello es especialmente malo quitarles la vida. Sin embargo, en nuestro país siguen matándolos impunemente. Basta con abrirles la puerta, pegarles un tiro y decir que se estaban fugando. No se investiga a nadie por no haber usado un dardo o alimentos con sedante.

\section{II.2. La cárcel}

Los homínidos no podemos sobrevivir en nuestro medio si no aprendemos de nuestros congéneres cómo hacerlo. Por ello, tenemos un cerebro diseñado para estar absorbiendo y procesando continuamente información compleja y ejercitarlo es para nosotros una necesidad. Siendo criaturas profundamente culturales, el aburrimiento absoluto nos resulta extremadamente estresante y dañino. Esta es la primera consideración relevante. La segunda consideración se refiere a la naturaleza intensamente social y afectiva de los homínidos. El aislamiento y la incomunicación con otros presos es temida en las cárceles todavía más que el castigo corporal. Por eso, no es de extrañar que los homínidos sufran intensamente enjaulados en solitario y separados de sus seres queridos, y desarrollen síntomas como la pérdida de pelo, por caída o arrancado, la anorexia, la bulimia y la autolesión.

La tercera consideración es de nuevo más compleja, pero es la que está más directamente relacionada con un posible derecho a la libertad como tal, que es algo distinto al derecho a no sufrir a consecuencia del aislamiento, el estrés y el aburrimiento absoluto que genera en los homínidos el encierro. Hay seres, como los peces de estanque, que no pueden imaginar una vida distinta de la que tienen. Los homínidos, en cambio, podemos imaginarnos a nosotros mismos en otro lugar y otro momento de nuestro pasado y también podemos imaginar el futuro. Esta capacidad nos hace conscientes del paso del tiempo durante nuestro cautiverio, y también nos hace enfurecernos porque nos obliguen a esta vida que no queremos y nos impidan continuar con la vida que teníamos, y con nuestros proyectos y familias. De hecho, algunos científicos que estudian la capacidad de planificación y engaño de los chimpancés, lo hacen observando cómo esconden y acumulan proyectiles con los que atacar a los humanos que van a mirarlos a los zoos donde están prisioneros (Osvath y Martin-Ordas 2015). Es más difícil defender un interés en la libertad en seres que no pueden concebir otra situación distinta de aquella en la que viven, o aquellos -por ejemplo, los niños-que tienen un interés fundamental en seguir vivos y en que no les hagan sufrir, pero no un interés fundamental en que nadie interfiera con sus designios, porque el que nadie gobierne su vida no es (todavía) un bien para ellos. 
Algunos autores han advertido que, de hecho, hablar de «liberación animal» puede inducir a error, dado que la inmensa mayoría de los animales tienen, como los niños, interés en seguir vivos y en vivir bien, pero no en vivir en libertad (Cochrane, 2006, 2009): si una pecera es demasiado pequeña para que el pez se ejercite adecuadamente, reduciendo su nivel de bienestar, mantener al pez en esa pecera va contra su interés en no sufrir, pero no va contra su interés en la libertad, porque los peces no tienen las características propias de los seres que poseen un interés en la libertad, como algo distinto e independiente de un interés en no sufrir. Es incluso difícil explicar en qué puede consistir la liberación de un pez que no puede distinguir un estanque en el que está prisionero de uno en el que no lo está. Estemos o no de acuerdo con esta posición, es fácil ver que no es lo mismo hablar del derecho a la libertad de un homínido que del derecho a la libertad de especies como los moluscos que viven pegados a las rocas y no pueden ni moverse ni lamentar su inmovilidad. Los homínidos sí podemos, podemos hacerlo físicamente y podemos hacerlo en nuestra imaginación y ello hace especialmente malo que nos aten o nos encarcelen. Si uno tiene la memoria y la inquietud mental del que ha nacido para aprender lo que otros saben por instinto, para viajar recorriendo grandes territorios, para inventar y para disfrutar creando, una pequeña celda vacía, sin ninguna distracción, produce numerosas patologías. Si uno es además intensamente social y afectivo, el aislamiento permanente es tan terrible como la absoluta inactividad. Es como ser enterrado en vida, que puede ser hasta peor que morir, por mucho que perdamos los homínidos al perder la vida. Si, además, podemos recordar la vida que teníamos y desear la liberación, nuestra frustración e indignación aumentará porque podemos imaginar algo distinto a aquello a lo que nos obligan. Un estudio reciente (Birket y Newton-Fisher, 2011) que incluyó chimpancés en grupos naturales y bien cuidados, con amplio espacio y programas de enriquecimiento, concluyó que todos los chimpancés cautivos examinados exhibían síntomas de trastorno mental, y no pudo encontrarse otra causa de sus conductas anormales que no fuese la mera cautividad. Sara -la chimpancé que a los cuatro años actuaba en el programa televisivo Crónicas Marcianas- presentaba conductas estereotipadas como el balanceo repetitivo y murió en 2012 en plena juventud. Su hermano Nico llegó a tal nivel de desesperación y desequilibrio mental que han tenido que amputarle al menos dos dedos por el daño que se produjo autolesionándose ${ }^{4}$. El sufrimiento que padecen los simios cautivos en nuestra sociedad, sin otro fin que nuestro posible entretenimiento, no es moralmente justificable y no debería contemplarse como algo normal en una sociedad que se supone alejada de la barbarie. De hecho, para seres con ciertas características emotivas y cognitivas el encarcelamiento y observación permanente es una forma de tortura (Gruen 2014: 231-47; Ross 2014: 57-77). Desafortunadamente, no es, además, la única.

\section{II.3. La tortura}

El derecho a no ser torturado es el más universal de todos los posibles derechos animales. Incluso un animal sin suficiente contigüidad psicológica para tener interés en su futuro, o sin suficientes capacidades como para distinguir un estanque donde está cautivo de otro donde no lo está, tiene interés en no padecer ese sufrimiento. Cualquiera que tenga capacidad de sufrir

4 Véase http://fundacionmona.org/nuestros-primates/chimpances/nico/10/12/2015 
tendrá un interés en no hacerlo. No obstante, si un homínido es torturado, la tortura le dolerá como le duele a los mamíferos que tienen un sistema nervioso diseñado, por ejemplo, para retirar una mano de algo que esté demasiado caliente. Pero, además, tendrá el sufrimiento añadido que se deriva de su memoria emocional a largo plazo. Esta memoria es diferente de la necesaria para recordar dónde se ha enterrado una nuez, y es esencial para la aparición de la moral, ya que es la que empleamos para saber a quién debemos estar agradecidos, a quien debemos castigar, o en quien podemos confiar. La memoria emocional no sólo almacena hechos, sino también la respuesta emocional al hecho, de forma que, incluso muchos años después, podemos revivir el sufrimiento padecido con gran intensidad. Así, nuestros torturadores no sólo nos hacen daño cuando nos torturan, sino que nos convierten para siempre en personas torturadas, con cicatrices emocionales, pesadillas y recuerdos que no logramos olvidar porque continúan causándonos indignación, frustración, resentimiento e incluso trastorno mental.

Nuestra capacidad para proyectarnos en el futuro hará, además, que nos sobresaltemos ante cualquier ruido, temiendo que vengan a por nosotros otra vez y nos dormiremos con miedo a despertar de nuevo maniatados, delante de un bisturí. Sabremos qué al día siguiente nos dolerá el costurón y que van a seguir experimentando con nosotros y haciéndonos cicatrices y temeremos también por nuestros seres queridos. En resumen, ciertas capacidades pueden intensificar y prologar el sufrimiento de tal forma que hacen la muerte, la cárcel y la tortura incluso peores de lo que ya son para cualquier animal ${ }^{5}$. Esta es la explicación no especista más plausible de qué tiene de especial torturar a los homínidos, humanos incluidos, aunque no deberíamos torturar a ningún animal.

Estos son los tres derechos homínidos recogidos en la Declaración de los Derechos de los Grandes Simios que defienden organizaciones internacionales como El Proyecto Gran Simio. Hay quien preferiría decir que lo explicado hasta aquí justifica la existencia de intereses fundamentales que tenemos razones sólidas para respetar, aun si no justifican la existencia de derechos. Y si lo que nos interesa es que se respete a los homínidos (humanos incluidos), bastaría con defender la existencia de obligaciones basadas en los intereses (interest-based duties), evitando así la discusión sobre los derechos. No obstante, la posibilidad de apelar a las obligaciones no es incompatible con explicar cómo podrían defenderse los derechos homínidos (o los humanos) desde distintas posiciones, como se hace a continuación, empezando por el primer debate.

\section{Derechos naturales y artificiales}

El debate sobre la existencia de derechos naturales está entre los debates más antiguos y complejos sobre los derechos ${ }^{6}$. Para tener una primera idea acerca del tema en cuestión,

5 El que algunas capacidades puedan aumentar el sufrimiento es compatible con que otras puedan reducirlo. El no poder dar sentido al dolor o predecir cuándo cesará, por ejemplo, puede hacerlo peor. Es por ello que algunas cosas que causan gran sufrimiento a un niño, como la oscuridad, o perderse en el supermercado, apenas afectan a un adulto. Y está claro que, al igual que un niño, un miembro de una especie con menos capacidad de comprender lo que le ocurre puede sufrir horriblemente.

6 Entre los defensores de los derechos naturales podríamos destacar a Cicerón, De Legibus (libro I, sec 28, aprox. $25 \mathrm{ac}$ ), Hugo Grotius (De jure belli ac pacis, 1625, Prolegómena) Samuel von Pufendorf (De Jure naturae et gentium, 1672), John Locke (Two Treatises on Government, 1689), Thomas Jefferson (United States Decla- 
supongamos que vamos en un barco con gentes de distintos países que encalla cerca de una isla deshabitada. Todos nos dirigimos a la costa más cercana, pero algunos nadan mejor y la alcanzan antes. Los últimos en llegar pueden encontrarse con una mano que les ayuda a salvarse o con una mano que les impide llegar a la playa, o incluso, que hunde su cabeza para siempre bajo el agua. Estamos en una situación como la que Hobbes denomina un «estado de naturaleza» (state of nature) caracterizado por la ausencia de una autoridad política central que pueda imponer algún tipo de orden. Pero no estamos en la situación que los filósofos llaman «de bote salvavidas» (life-boat situation), es decir, una situación de escasez extrema, porque la isla es tan grande y fértil que todos podrían vivir en ella tranquilamente el resto de sus vidas.

En estas circunstancias la mayoría de la gente diría que todos los náufragos tienen derecho a que les dejen llegar a la playa, y que este derecho es natural o inherente a la naturaleza de las personas, y no depende de algo que previamente haya hecho alguien para darles ese derecho. No importa que procedan de la misma cultura y compartan ciertas convenciones o creencias, o que el capitán sobreviva y mantenga el mando, y con ello parte de la «polis», garante de los derechos legales, de la que zarparon. Y no importa su raza o condición. Por esto, los derechos humanos suelen considerarse naturales y no, por ejemplo, algo que surge sólo cuando alguien los pone por escrito o los incluye en una declaración.

Sin embargo, hay quienes piensan que los únicos derechos o deberes que hay son los que en un momento dado nos hemos inventado. Estos autores no sólo piensan esto de algunos derechos (o deberes) -como el de aparcar entre rayas de pintura de ciertos colores- sino de todos los derechos (y deberes), incluido el derecho a alcanzar la orilla, o a vivir en libertad. Piensan que todos son igualmente artificiales: si los tenemos es solamente por algo que han hecho los humanos o sus órganos de gobierno, como seguir una tradición, consignarla por escrito o levantarse en armas y hacer que una lista de preceptos se respete. Esta es la posición que asumen muchos defensores del relativismo cultural, que piensan que el que algo sea malo o injusto depende enteramente del contexto cultural.

Los que cuestionan este relativismo argumentan que si lo que no es permisible en un contexto puede serlo en otro, no es porque cambien los principios, sino porque cambian las circunstancias. Por ejemplo, el principio según el cual no se debe dañar a las personas innecesariamente no cambia, aquello que daña sí: puede variar con las condiciones geográficas -no es lo mismo quitarle a alguien unos cubitos de hielo en el Sáhara o el Polo- o las condiciones culturales. Por ejemplo, cuando las razones por las que algo es dañino están relacionadas con las expectativas de las personas, en lugares donde las expectativas son distintas, también habrá distintas cosas dañinas e impermisibles. No es lo mismo mentir en una cultura donde hay gran aversión a la mentira -quizá porque recibir información correcta, por ejemplo, sobre el grosor del hielo, es cuestión de vida o muerte- que mentir en una sociedad donde todos esperan que mientas y exageres por cortesía, por quedar bien o para entretener a los demás.

ration of Independence, 1776), o Thomas Paine (Rights of Man,1791). Entre sus detractores destacan Jeremy Bentham («Critique of the Doctrine of Inalienable, Natural Rights» en sus Anarchical Fallacies (1843) y Hans Kelsen (1928) «The Idea of Natural Law,» en Essays in Legal and Moral Philosophy (1973) ed. O. Weinberger, trans. P. Heath. Dordrecht: Reidel. 
Los derechos simios no dependen de esta discusión. Hay defensores de los derechos simios que creen que hay derechos universales e inalienables que se explican haciendo referencia a la naturaleza de estos seres y sus características, y otros defensores de los derechos simios como mi amigo Jesús Mosterín (2014, 89 y ss.) que piensan que todos los derechos son igualmente artificiales. La cuestión de si los simios (o los perros) tienen o no ciertos derechos es para ellos muy sencilla: todo depende de qué derechos decidamos darle. Esto no significa que todo valga. Uno debe también justificar qué convenciones cree que su sociedad debe adoptar. Según estos autores, si debemos otorgar derechos a los simios o a las mujeres es porque hay mejores razones para adoptar estas convenciones que para no adoptarlas. Estas razones, cuando uno las solicita, suelen terminar haciendo referencia a capacidades o intereses de los sujetos de los supuestos derechos inventados. Así que lo que en principio parecen posiciones irreconciliables terminan mucho más cerca de lo que cabía suponer. Y, además, el hecho de que algunos no quieran hablar de «derechos homínidos» sino de «derechos que se deberían otorgar a los homínidos», ni de «derechos de las mujeres» sino de «derechos que se deberían otorgar a las mujeres» no tiene por qué tener implicaciones diferentes respecto a cómo debemos tratar ni a los simios ni a las mujeres?

\section{Estatus y función: la base de los derechos}

Según la teoría del estatus, ciertos individuos tienen unas características que hacen que sea apropiado atribuirles ciertos derechos y respetar tales derechos tanto si ello beneficia a estos individuos como si no. En cambio, según las teorías instrumentalistas, los derechos protegen nuestros intereses fundamentales. Protegernos es su razón de ser. Warren Quinn distingue ambas posturas y defiende la primera como sigue:

«no es que nos parezca apropiado adscribir derechos [a ciertos individuos] porque pensamos que sería bueno que tales derechos sean respetados. Más bien, pensamos que si respetar tales derechos es bueno, es precisamente porque de hecho tales individuos los tienen.» (Quinn, 1993, 73)

Como explica unas páginas antes, es apropiado que ciertos individuos tengan la última palabra en relación a lo que se les va a hacer, no porque ésta sea «la mejor forma de proteger el bienestar general de la humanidad» (Quinn, 1993, 170, énfasis añadido), sino porque «sería indigno» no reconocer este poder en un «ser independiente», «que tiene sus propias metas» (ibid, su cursiva) ${ }^{8}$.

7 Nótese que puede defenderse la idea de que los difuntos, los niños, y la generaciones futuras tienen derechos no naturales porque para tener derechos no es necesario inventarlos uno mismo, basta que alguien los invente o establezca.

8 Otro defensor de la teoría del estatus es Robert Nozick, que comienza su obra más importante Anarchy, State and Utopia con la frase «Los individuos tienen derechos y hay cosas que ninguna persona o grupo les puede hacer (sin violar sus derechos)» (Nozick, 1974, ix). 
Un defensor del instrumentalismo podía responder que no es muy importante que la palabra empleada sea «indigno» siempre que estemos de acuerdo en que se trata de algo malo9. Las razones por las que es malo pueden referirse al «bienestar general», como dice Quinn, o a otras razones. Al referirse sólo al bienestar general, Quinn confunde el instrumentalismo con el instrumentalismo utilitario, que es la variante más conocida, pero quizá no la mejor. El utilitarismo es una teoría consecuencialista (juzga los actos exclusivamente por sus resultados), bienestarista (juzga los resultados exclusivamente en términos de experiencias positivas y negativas, o de satisfacción o frustración de preferencias) y agregacionista (juzga los resultados por la suma total de bienestar, sin atender a su distribución). El utilitarismo recomienda que actuemos de modo que la suma de bienestar sea la mayor posible, pero no prescribe cómo. Y muchos utilitaristas creen que defender derechos individuales contribuye, más que negarlos, a que el bienestar general sea el mayor posible. Esto da lugar al llamado utilitarismo indirecto o de dos niveles, en que el nivel superior permite explicar la existencia del nivel inferior, derechos incluidos, en términos utilitarios. Ahora bien, el mismo modelo arquitectónico podría contener una filosofía igualitaria que explicase los derechos individuales defendidos en el nivel inferior en base a la igualdad moral de todos los seres humanos o como la mejor formar de protegerla. Análogamente, un suficientario como Harry Frankfurt (1987), es decir, alguien que mantiene que lo importante no es la igualdad sino que todos tengan lo suficiente podría explicar la defensa de tales derechos como la mejor forma de garantizar que nadie tenga menos que lo suficiente. Y también, un prioritario como Derek Parfit (1995), es decir, alguien que piensa que beneficiar a alguien tiene más valor moral cuanto peor esté ese alguien, puede defender los derechos como la mejor forma de proteger a los que están en una situación peor. Incluso una teoría contractualista, como la de Thomas Scanlon (1998), puede defender los derechos como la mejor forma de llegar a una situación que nadie pueda rechazar razonablemente y un rawlsiano podrá describir tal situación en términos de equidad (fairness).

Hoy en día, en filosofía política es normal ofrecer una fundamentación instrumentalista, y hay también quien se inclina por una posición híbrida que incluye elementos de ambas teorías (Sen 1998). Los derechos simios pueden defenderse de este modo, como la mejor forma de proteger la vida, la libertad y el bienestar de los homínidos. No obstante, los derechos de los simios también pueden defenderse desde una teoría del estatus. Por ejemplo, Agnieszka Jaworska (2007) defiende, en la prestigiosa revista Ethics, una teoría de los derechos homínidos basada en el concepto del estatus moral completo (full moral standing). Tras analizar el caso de la gorila Koko, concluye que todos los animales tienen cierto estatus moral, pero sólo algunos tienen ciertas características, como la capacidad de preocuparse por otros y cuidar de ellos (the capacity to care) que justifican un estatus moral completo. Jaworska incluye a todos los grandes simios, incluidos los humanos, en esta categoría.

9 De hecho, hay quienes califican precisamente de «indigno» el negar derechos a ciertos animales (por ejemplo, Lara y Campos, 2015, 68). 


\section{Intereses y elección: la justificación de los derechos}

La distinción entre estatus y función está estrechamente relacionada con otra distinción empleada con mayor frecuencia. Se trata de la distinción entre la teoría del interés (interest theory) y de la elección (choice theory), que a veces se llama también de la renuncia (waive theory) o de la voluntad (will theory). Según la primera, el derecho de los náufragos a alcanzar la orilla se basa en lo importante que es para ellos que les dejen ponerse a salvo. La isla no tiene derechos porque no tiene intereses; un niño, en cambio, si los tiene. La teoría rival mantiene que la posesión de derechos no está ligada a los intereses sino a la voluntad o capacidad de elegir ${ }^{10}$. Si los náufragos pueden elegir entre llegar a la playa o ahogarse, entonces tienen derecho a llegar a la playa. Es decir, si los náufragos tienen derecho a salvarse es precisamente porque pueden decidir suicidarse -son «pequeños soberanos» sobre ese dominio y pueden hacer lo que quieran con su vida. Otros, en cambio, tienen que obtener su consentimiento para hacerles algo (Hart, 1982, 183). Dada la relación que estos teóricos ven entre tener derechos y poder elegir, no sorprende que en su opinión los derechos inalienables no existen -aunque tampoco es absurdo creer en los derechos inalienables de los electores. Los derechos inalienables son aquellos que no podemos dejar de tener, por ejemplo, vendiéndoselos a otros, como el derecho a votar o a ser libre. Según la teoría electiva uno puede venderse a sí mismo como esclavo o incluso vender su vida y su cuerpo a un caníbal como parece que hizo Bernd Jürgen Armando Brandes en Alemania, que dio su consentimiento para que otro lo matase y se lo comiese ${ }^{11}$. Esta es una consecuencia directa de una teoría electiva como la de Hillel Steiner, donde «todos los derechos son en esencia derechos de propiedad» $(1994,93)$. No hay problema, por tanto, en que podamos vendernos o regalarnos a un caníbal.

La consecuencia más grave de esta teoría es que los que no pueden renunciar carecen por completo de derechos. Las generaciones futuras no tienen ningún derecho porque como todavía no están aquí, aun no pueden aceptar ser devorados, o que devoremos el planeta. Así que tampoco tienen derecho a que les dejemos un planeta habitable. Los niños ya están aquí, y ya tienen intereses muy reales, pero como todavía no tienen la capacidad de rechazar ofertas, no tienen tampoco derecho alguno, por ejemplo, a que no les golpeemos sin razón. Lo mismo le ocurre a las generaciones pasadas, a los difuntos, a los comatosos y a todos los que carecen de la capacidad de declinar ofertas, ya sea por edad, minusvalía, accidente o enfermedad. Al perder esta capacidad pierden todos sus derechos. Sin embargo, HAL, el computador de 2001. Una odisea espacial, que decide desobedecer y guiar la nave según sus criterios, sí puede ser un sujeto con derechos (Steiner, 1994, 249, n 27).

La mayoría de los filósofos morales y políticos y de la gente en general, no comparten estas extravagancias libertarias. Piensan que los derechos, como la ética en general, tienen más que ver con la idea de reducir el sufrimiento o proteger intereses fundamentales que con la capacidad de elegir. Los niños no puedan rechazar la oferta de que no abusen de ellos, por ejemplo -ni tampoco pueden dar su consentimiento. Pero esto no nos da razones para negarles el derecho a no ser víctimas del abuso, o a tomarnos este derecho menos en serio. Al

10 Entre los pensadores que relacionan los derechos con los intereses se incluyen David Lyons, Neil McCormick, Mathew Kramer y Joseph Raz. Entre los pensadores que relacionan los derechos y la voluntad están Enmanuelle Kant, Friedrich Carl de Savigny, Herbert Hart, Hans Kelsen, Carl Wellman y Hillel Steiner (Wenar 2015).

11 http://www.nytimes.com/2006/05/09/world/europe/09iht-web.0509cannibal.html?_r=0 (10/12/2015) 
revés, nos da razones para protegerlos más, porque esa incapacidad les hace más vulnerables y más necesitados de la protección que nos dan los derechos ${ }^{12}$. Además, mientras que los científicos confirman y explican cada vez mejor los intereses fundamentales que los derechos protegen, cada vez explican causalmente más conductas que hasta ahora atribuíamos a la libre elección. Realmente, ni siquiera sabemos bien qué significa «poder elegir», ni si cuánto más podamos elegir, más derechos tendremos. Tampoco está claro si basta con poder elegir o renunciar a algo (por ejemplo, al postre) para tener todos los derechos, o si poder renunciar al postre sólo nos da derecho al postre, pero no derecho al alimento en general, que es algo que solo conseguiremos los que seamos capaces de matarnos de hambre a voluntad. Si bastase con poder elegir algo (cosa que logra cualquier simio), nos encontraríamos con una postura cuya explicación más plausible se refiere a los intereses del tipo de agente sofisticado que tienen la capacidad de elegir, con lo cual estaríamos volviendo a la visión estándar de los derechos como protectores de intereses. Si insistimos en que no podemos tener derecho a nada concreto a lo que no podamos renunciar, esta postura parece aun más arbitraria. Además, lo normal es pensar que tenemos derecho a un aire respirable o al agua potable precisamente porque no podemos renunciar a ello. Sería absurdo pensar que la gente que tiene vértigo o pánico al fuego tiene menos derechos a que los bomberos los salven de un edificio en llamas porque no pueden saltar o renunciar a saltar como los demás sino que habrá que empujarlos para que salten o sujetarlos para que no salten antes de tiempo. Sería absurdo perder el derecho a lo que más necesitamos por ser incapaces de renunciar a ello.

En cualquier caso, y por implausible que nos parezca esta teoría, no hace falta rechazarla para defender los tres modestos derechos homínidos, porque los homínidos también pueden elegir. Por ejemplo, no sólo los simios, sino también otros primates como los monos capuchinos se niegan a comer si cada vez que le dan a la palanca que les permite obtener comida, un congénere de otra jaula recibe un shock eléctrico. Algunos de los sometidos a este experimento llegaron a estar doce días sin comer para no hacer sufrir a los demás (De Waal, 2006, 178). Las elecciones de un chimpancé pueden ser tan complejas que el propio Franz de Waal compara sus estrategias con los comentarios de Tucídides sobre las guerras del Peloponeso.

Jeroen tenía dos opciones. Podía aliarse al jugador más fuerte, Luit, y obtener algunos beneficios a cambio, -los beneficios que Luit decidiese darle. También podría ayudar a Nikki a que retase a Luit y crear así a un nuevo macho alfa, que le debiese el puesto... Como super-potencia de la colonia, realmente Luit no necesitaba más que la neutralidad del viejo simio. Apoyar a Nikki era la elección lógica de Jeroen. Sería el director de las marionetas, y disfrutaría de más poder del que podría haber soñado tener bajo el mandato de Luit. (De Waal, 2006, 71)

12 No todos los intereses están ligados a un derecho, ni todos los derechos a un interés, si tomamos los casos de forma aislada, sin tener en cuenta al conjunto de los individuos con intereses. Uno puede tener mucho interés en que otro caiga enamorado a sus pies, sin adquirir por ello ningún derecho; y un juez puede tener derecho a multarnos sin tener interés alguno en ello. No obstante, si tomamos a otros individuos en cuenta, veremos que tener que corresponder los sentimientos ajenos puede ser opresivo e imposible y que es la sociedad la que tiene interés en los poderes que delega en un juez. 
Dado que los simios pueden elegir, aun los que suscriben la teoría de que sólo los que eligen tienen derechos, pueden apoyar los derechos de los simios. Esta es al menos la postura de Hillel Steiner uno de los principales representantes contemporáneos de la teoría electiva, que respondió a esta cuestión como sigue:

En vista de los hechos referidos [por de Waal] no puedo ver ninguna razón para negar que los grandes simios o a los delfines puedan tener derechos en el sentido de la teoría electiva. Al parecer, poseen los atributos salientes de la agencia moral -la capacidad para hacer distinciones normativas, la capacidad de autocontrol y la capacidad de percibir complejas relaciones causales. Normalmente, esto basta para que un individuo tenga derechos. El hecho de que yo defienda la teoría electiva no significa que rechace vuestro proyecto. Al contrario, me veo muy inclinado a adherirme.

Mike Otsuka me ha sugerido la plausible idea de que tener derechos en el sentido de la teoría electiva no tiene porque ser una cuestión de todo o nada. Quizá deberíamos identificar una escala de estatus en base a características como ...el grado de impedimento cognitivo o volitivo... ${ }^{13}$.

Cuando estas diferencias de grado son tan grandes que modifican los intereses del individuo como se explica en la sección II, comparando un humano y un molusco o un mosquito, no hay arbitrariedad. Pero no es plausible afirmar que los humanos más inteligentes tienen más derecho a que no les torturen que otros humanos menos inteligentes, aunque los intereses de ambos sean idénticos y los efectos de la tortura también. Pese a lo repugnante que pueda resultarnos esta postura, todavía es compatible con los derechos simios, dado que los tres derechos solicitados podrían encajar perfectamente en el nivel inferior de capacidad, mientras que la lista completa de derechos humanos se reservaría para individuos más capaces.

Una variante de la teoría electiva exige que, además de elegir, uno pueda tener obligaciones. El pensador cristiano y conservador Roger Scrutton (2007) apela a esta idea para defender la caza de zorros y rechazar los derechos animales. Esta postura dejaría sin derechos no solo a los difuntos y a los niños sino incluso a aquellos que teniendo intacta su capacidad de elegir no pueden por minusvalía o enfermedad tener obligaciones ya que no pueden satisfacerlas y deber presupone poder («ought implies can»). La posición de Scrutton ha sido criticada en sus distintas versiones por Christine Korsgaard (2012, 2014). La menos atractiva de las versiones de esta posición -y que ni siquiera Scrutton aceptaría- excluiría a los niños o los minusválidos porque como no son una amenaza para nosotros, no tenemos que concederles derechos, ya que poco pueden hacer al respecto. Una versión menos cruda de esta idea apela a la reciprocidad para no darles derechos al menos que tengan también obligaciones. La versión más atractiva es la que entiende que aquellos que tienen obligaciones tienen un nivel de sofisticación cognitiva que les hace tener intereses, por ejemplo, en seguir vivos, según se explica en la sección II. Pero esto ya sería volver a la teoría estándar de los derechos. En cualquier caso, los homínidos

13 Hillel Steiner, comunicación personal, mensaje electrónico 9.11.2007. 
viven en grupos socialmente muy complejos donde tienen derechos y obligaciones. Por ejemplo, los machos chimpancés hacen pactos de mutua defensa, de modo que cuando uno es atacado, el otro tiene la obligación de defenderle. Si no lo hace, el agredido se defenderá sólo y luego perseguirá al aliado cobarde para castigarle por no haber cumplido con su obligación. También suelen liderar en coalición, manteniendo una división del trabajo político a realizar, como la defensa de grupos extraños o la disolución de conflictos internos, obligaciones que no pueden ignorar o podrán perder su posición de mando. Las hembras bonobo forman también fuertes alianzas donde adquieren numerosas obligaciones que no sólo incluyen la defensa y el reclutar a los hijos varones mayores para la defensa, sino atención con los partos y los bebés. Además de las obligaciones con los amigos y aliados, los homínidos tienen obligaciones de grupo como avisar de peligros o posibles beneficios. Y tienen también numerosas obligaciones familiares. Los gorilas viudos, por ejemplo, han de hacer nidos donde sus hijos puedan dormir todos a su lado. Los homínidos conocen sus obligaciones y cuando aprenden a hablar inglés (entendiendo el habla y expresándose mediante el lenguaje de signos) no tienen dificultad a describirse a sí mismos como «malos» cuando no las cumplen (White Miles 1993: 52). En esos casos evitan la mirada, andan cabizbajos, muestran una sonrisa nerviosa, y adoptan posturas sumisas esperando una riña. Su conducta sugiere que entienden el motivo de la misma. De Waal relata, por ejemplo, como unas chimpancés adolescentes amonestadas por otros chimpancés por haber llegado tarde a cenar, fueron las primeras en la fila al día siguiente. Entendieron que fueron castigadas por llegar tarde y por eso a la siguiente oportunidad fueron las primeras en la cola. Esto ocurrió pese a que, tras haber llegado demasiado tarde como para dormir con los demás, los miembros adultos del grupo no pudieron castigarles hasta entrado el día siguiente ${ }^{14}$. Así pues, ni siquiera esta última postura imposibilita los derechos simios, aunque nadie debería querer emplearla ya que niega la protección que ofrecen los derechos a aquellos que más la necesitan como los enfermos, los discapacitados y los niños, además de a nuestros nietos y biznietos aun no nacidos y a nosotros mismos cuando seamos ancianos y luego difuntos.

\section{La concepción de los derechos como metas o constricciones}

Cualquiera que sea la teoría de los derechos que uno defiende, todos los filósofos consideran a los derechos como algo que tiene especial peso normativo. Ronald Dworkin (1984) compara los derechos con los triunfos de una baraja. Un triunfo tiene más peso que varias cartas bajas. Como ilustración, pensemos en el caso de los juegos romanos en que se arrojaban esclavos a los leones. El derecho a la vida de un esclavo tiene mucho más peso que la diversión de muchos romanos, por mucha que esta fuese. Podría decirse que su derecho a vivir «triunfa» sobre el interés en divertirse de la multitud. Esta concepción es perfectamente compatible con los derechos homínidos. Por ejemplo, el derecho del chimpancé a seguir viviendo libre en su selva «triunfa» sobre el deseo que alguien pueda tener de entretenerse viéndole enjaulado en el zoo, y su derecho a la vida «triunfa» sobre el deseo de comerse un exótico asado de bushmeat.

14 http://proyectogransimio.org/videos/nuestros-videos/entrevista-a-frans-de-waal (10.12.2015). 
Consideremos ahora otra concepción de los derechos o al menos de algunos derechos como el derecho a la vida. Como ilustración, pensemos en el problema del tranvía (the trolley problem) ideado por Philippa Foot (1967). Vamos en un tren sin control que va a tomar la vía derecha donde atropellará cinco inocentes. Tirando de la palanca no podemos parar, pero sí desviarnos a la vía izquierda, donde sólo atropellará a uno. Si pensamos que los derechos son metas hacia las que hay que correr, intentaremos salvar el mayor número de vidas. Si pensamos que los derechos son meras barreras o constricciones, como las vallas de un maratón que marcan la pista por donde se puede correr, dejaremos que el vagón siga su curso. No importa llegar a la meta, sólo el respetar las barreras.

Contra lo que suele suponerse, la concepción de los derechos como constricciones no implica que los derechos se consideren sagrados o muy importantes. Todo lo que indica es que no se puede violar un derecho para minimizar la violación de derechos (Nozick, 1974, 28ff). Uno puede pensar que no se debe robar un euro o un coche para impedir el robo de miles de euros o de coches. Esto es compatible con no considerar esos robos algo importante. Esta teoría es especialmente implausible cuando no permite violar derechos ni siquiera para impedir una violación masiva de derechos de rango superior. Por ejemplo, es ridículo decir que no podemos robar cinco euros, para hacer una llamada y salvar a cinco inocentes de un asesino. Sin embargo, hay libertarios que consideran cualquier impuesto sobre su trabajo, por pequeño que sea, una violación impermisible, incluso para salvar vidas. En todo caso, la idea de que al menos algunos derechos son constricciones, no metas, todavía es compatible con los derechos homínidos. Agnieszka Jaworska (2007), por ejemplo, mantiene que como los homínidos tienen un estatus moral completo, se podría matar un pollo para salvar a cinco pollos, pero no se puede matar a un gorila para salvar a cinco.

\section{Derechos negativos y positivos}

Hay quienes niegan la existencia de derechos positivos, por ejemplo, a la educación o la salud. Piensan que la justicia exige que no nos hagan daño, pero no exige que nos ayuden. Los que niegan los derechos positivos son de nuevo los libertarios ${ }^{15}$. En cualquier caso, esta distinción entre derechos positivos y negativos, que además ha sido muy criticada (McCallum, 1967; Sterba, 1998, 238; Dworkin, 2001) es irrelevante para la defensa de los derechos simios, porque todos los derechos exigidos en la Declaración de los Derechos de los Grandes Simios son derechos negativos. El derecho a que no te maten, no te encarcelen y no te torturen son sólo derechos a que te dejen en paz. Por tanto, cualquiera que sea nuestra posición sobre los derechos positivos, no es incompatible con la defensa de los tres derechos homínidos que se han venido solicitando hasta ahora.

Esto no significa que no puedan tener más derechos, ni que todos hayan de ser negativos. La idea de que los animales tienen sólo derechos negativos está muy extendida incluso entre los defensores de los animales (De Lora, 2007). Sin embargo, hay también autores que consideran que si los humanos tienen derechos positivos, sería especista suponer que otras

15 Entre los libertarios progresistas como Hillel Steiner, Michael Otsuka o Peter Vallentyne esta opinión no tiene las graves consecuencias que podría tener porque otras partes de sus teorías, como las relativas al reparto de los recursos naturales, permiten a los necesitados acceder a recursos naturales suficientes como para no depender del trabajo de los demás. 
especies no los tienen (Horta 2012, 2013, Faria 2013, 2014). Una cosa es que pueda ser difícil, arriesgado, contraproducente o demasiado costoso intervenir en la naturaleza, que sin duda puede serlo. Y otra, negar categóricamente el derecho a la ayuda a otras especies, sin más justificación que su pertenencia a otras especies. Supongamos que, al cruzar un campus universitario para ir a dar una clase, un profesor de ética cree ver a un niño ahogándose en un pequeño lago. Al acercarse, se da cuenta de que en realidad se trata de un pequeño homínido que alarga su manito hacia él, pidiéndole ayuda ${ }^{16}$. Como no le apetece mojarse los pies, al ver que el bracito es demasiado peludo para ser humano, el profesor decide dejarle morir. ¿Es esto defendible? Está claro que no, pues aunque este profesor no esté obligado a salvar a todos los homínidos del planeta, está obligado a salvar a este pequeño homínido, al que puede salvar con seguridad y con un esfuerzo muy modesto.

\section{Compatibilidad múltiple}

Hay un notable solapamiento entre los que defienden (i) que solo hay derechos negativos (ii) que los derechos (o al menos algunos derechos) son constricciones en vez de metas (iii) que solo tienen derechos los que pueden rechazar ofertas (iv) y quienes piensan que el estatus moral es la base de los derechos. Incluso la cuestión de si hay derechos naturales ha estado ligada, históricamente, a esta cuestión. Se ha asumido que si tenemos derechos naturales están relacionados con nuestra naturaleza racional, que es la que nos da la capacidad de elegir y con ello nuestro estatus moral. Sin embargo, hay muchas coincidencias en la historia de la filosofía que son solamente consecuencia de que dentro de una corriente, como la libertaria, se mantengan varias ideas. Aunque sea típico del libertario creer en los derechos naturales y la teoría electiva y negar los derechos positivos, no hay contradicción en mantener que los derechos naturales se explican por su función de proteger intereses fundamentales del individuo y que pueden, además, ser derechos positivos. También se puede defender una teoría del estatus como la de Jaworska, que no coincide con la teoría electiva. Asimismo, no habría contradicción en pensar que únicamente los que pueden elegir tienen derechos, y que estos derechos son tanto positivos como negativos. La lógica permite muchas más combinaciones de las que han sido frecuentes en la historia del pensamiento político europeo. Los derechos naturales, por ejemplo, pueden defenderlos conservadores o progresistas, con o sin referencia a la divinidad. Y todas las posturas son compatibles con los derechos homínidos, incluso si tenemos en cuenta no solo las posturas que se han mantenido sino las que se podrían mantener sin contradicción. De hecho, hay todavía más posiciones posibles que las que he mencionado aquí. Por ejemplo, al final de la segunda sección, me he referido a la posibilidad de prescindir del término «derecho» y hablar únicamente de las obligaciones basadas en los intereses (interest-based duties). Otra forma de abordar la cuestión, es la de centrarse no en afirmar que los simios tienen derechos sino en negar que los humanos tenga derecho a matar o enjaular a los simios. Este es, por ejemplo, el planteamiento que ahora prefiere Lee Hall, una catedrática de derecho autora del primer legal brief en defensa de un simio (Hall y Waters 2000).

16 Véase un delfín en apuros pidiendo ayuda a un buzo https://www.youtube.com/watch?v=i2geGkc5y1Y y a una yubarta dando las gracias tras ser asistida, https://www.youtube.com/watch?v=tcXU7G6zhjU (10.12.2005) 


\section{Conclusión}

Hay muchas opiniones respecto al origen, la función o la naturaleza de los derechos que pueden combinarse de muchas formas posibles, y los derechos simios pueden defenderse desde las posiciones más diversas. Hay posturas que mantienen muy pocos autores, generalmente comprometidos con el libertarismo político. La opinión mayoritaria es que los negros ya tenían derecho a que no les esclavizasen antes de que el estado aboliese la esclavitud, y que éste es un derecho natural e universal que protege nuestro interés en la libertad. La mayoría pensamos también que los derechos tienen la función de proteger intereses fundamentales, que se puede violar un derecho menor para proteger otro más importante, y que no todos los derechos son negativos. La opinión mayoritaria facilita la defensa de los derechos homínidos, pero incluso un libertario con ideas tan minoritarias como Hillel Steiner puede aceptar los derechos homínidos. No es cierto, por tanto, que defender los derechos homínidos requiera estar confundido respecto a lo que es un derecho o asumir posiciones excéntricas en algunos de los principales debates en torno a los derechos ${ }^{17}$.

\section{Referencias}

Beitz, Ch. (2013), «Human Dignity in the Theory of Human Rights. Nothing but a Phrase?» Philosophy and Public Affairs 41, pp. 359-290.

Berger, L.R. (2001), Viewpoint. Is it Time to Revise the System of Scientific Naming? National Geographic News, http://news.nationalgeographic.com/news/2001/12/1204_ hominin_id.html

Birkett, L.P. y Newton-Fisher, N. (2011), «How Abnormal is the Behaviour of Captive-Zoo Living Chimpanzees?» PLoS ONE 6.6. e20101. Doi:101371/journal pone.0020101.

Cavalieri, P. and P. Singer eds. (1993), The Great Ape Project, New York: St Martin Press.

Cochrane, A. (2006), Animal Rights without Liberation, Columbia USA: Columbia University Press.

Cochrane, A. (2009), «Do Animals Have an Interest in Liberty?», Political Studies 57, pp. 660-679.

De Lora, Pablo (2007), «Los animales y el gobierno de la naturaleza» A. Herrera (ed.) De animales y hombres, Oviedo: Biblioteca Nueva y Ediciones de la Universidad de Oviedo, pp. 97-116.

De Waal, F. (2006), Our Inner Ape, Nueva York: Riverhead.

Dworkin R. (1984), «Rights as Trumps», J. Waldron (ed.) Theories of Rights, Oxford: Oxford University Press, pp. 153-67.

Dworkin R. (2001), «Do Values Conflict? A Hedgehog's Approach», Arizona Law Review 43, pp. 251-9.

Faria, C. (2013), «Differential Obligations towards Others in Need», Astrolabio 15, pp. $242-46$.

Faria, C. (2014), «Equality, Priority and Non Human Animals», Dilemata 13, pp. 225-236.

17 Agradezco mucho los comentarios de Oscar Horta y Andrew Williams, así como de los editores de Daimon y de dos árbitros anónimos. 
Foot, P. (1967), «The Problem of Abortion and the Doctrine of the Double Effect», Oxford Review 5, pp. 5-15.

Frankfurt, H. (1987), «Equality as a Moral Ideal», Ethics 98, pp. 21-45.

Goodin, R., C. Pateman y R. Pateman (1997), «Simian Sovereignty», Political Theory 25, pp. 821-849.

Gruen, L. (2014), «Dignity, Captivity and an Ethics of Sight», en L. Gruen (ed.) The Ethics of Captivity, Oxford: Oxford University Press, pp. 231-247.

Hall, L. y A. Waters (2000), https://www.scribd.com/doc/161084876/From-Property-to-Person-The-Case-of-Evelyn-Hart

Hart, H.L.A. (1955), «Are there Any Natural Rights?» The Philosophical Review 64, pp. 175-191.

Hart, H.L.A. (1982), «Essays on Bentham», Studies in Jurisprudence and Political Theory, Oxford: Clarendon Press.

Horta, O. (2012), «Tomándonos en serio la consideración moral de los animales: más allá del especismo y el ecologismo», J. Rodríguez Carreño (ed.) Animales no humanos entre animales humanos, Plaza y Valdés, pp. 191-226.

Horta, O. (2013), «Zoopolis, Intervention, and the State of Nature», Law, Ethics and Philosophy 1, pp. 113-25.

Holtug, N. (2007), «Equality for Animals», J. Ryberg, T. Petersen and C. Wolf (eds.) New Waves in Applied Ethics, Basingstoke: Palgrave Macmillan, pp. 1-24.

Jaworska, A. (2007), «Caring and Full Moral Standing», Ethics 117, pp. 460-97.

Korsgaard, C. (2012), «A Kantian Case for Animal Rights» in J. Haenni, M. Michel and D. Kuehne (eds.) Animal Law-Tier und Recht. Zurich: Dike Verlag-Berliner WissenschaftsVerlag, pp. 3-37.

Korsgaard, C. (2013), «Kantian Ethics, Animals, and the Law» Oxford Journal of Legal Studies, 33, pp. 1-20.

Nagel, T. (1979), Mortal Questions, Cambridge: Cambridge University Press.

Nozick, R. (1974), Anarchy, State and Utopia, Oxford: Blackwell.

Lara, F. y O. Campos (2015) Sufro, luego importo, Madrid: Plaza y Valdés.

MacCallum, G.C. (1967), «Negative and Positive Freedom», The Philosophical Review 76, pp. 312-334.

MacMahan, J. (2002), The Ethics of Killing, Oxford: Oxford University Press.

Marshall, M.H. et al (ed.) (1994) The Development of Future-Oriented Processes. Chicago. University of Chicago Press.

Mosterín, J. (2014), ; Vivan los animales! Madrid. Alianza Editorial.

Osvath, M. \& Martin-Ordas, G. (2015), «The Future of Future-Oriented Cognition in Nonhumans. Theory and the Empirical Case of the Great Apes», Philosophical Transactions of the Royal Society B 369: 20130486. http://dx.doi.org/10.1098/rstb.2013.0486

Osvath, M. and Osvath H., (2008), «Chimpanzee (Pan troglodytes) and Orangutan (Pongo Abelii) Forethought: Self-control and Tool Experience in the Face of Future Tool Use». Animal Cognition 11: 661-674.

Parfit, D. (1995), «Equality or Priority», The Lindley Lecture, University of Kansas.

Rawls, J. (1999), A Theory of Justice, Cambridge: Belknap Press. 
Ross, S. R. (2014), «Captive Chimpanzees» in L. Gruen (ed.) The Ethics of Captivity. Oxford: Oxford University Press, pp. 57-77.

Scanlon, T. (1998), What we Owe to Each Other, Cambridge Mass: Harvard University Press.

Scrutton, R. (2007), Animal Rights and Wrongs, London: Continuum.

Sen, A. (1982), Philosophy and Public Affairs 11, pp. 3-39.

Steiner, H. (1994), An Essay on Rights, Oxford: Blackwell.

Sterba, J.P. (1998), «From Liberty to Welfare», J. Sterba (ed.) Ethics: The Big Questions, Malden, MA: Blackwell.

Quinn, W. (1993), Morality and Action, Cambridge: Cambridge University Press.

Wennar, L. (2015), «Rights», E.N. Zalta (ed.) The Stanford Encyclopedia of Philosophy http://plato.stanford.edu/

White Miles, L. (1993), «Language and the Orangutan: The Old person of the Forest», P. Cavalieri and P. Singer (eds.) The Great Ape Project, pp. 42-58.

Wise, S. (2000), Ratling the Cage, Cambridge: Perseus. 
